Research paper

\title{
Interpersonal psychotherapy as add-on for treatment-resistant depression: A pragmatic randomized controlled trial
}

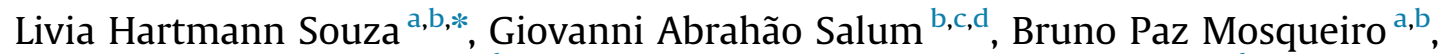 \\ Marco Antonio Caldieraro ${ }^{\mathrm{a}, \mathrm{b}}$, Tadeu Assis Guerra ${ }^{\mathrm{a}, \mathrm{e}}$, Marcelo P. Fleck ${ }^{\mathrm{a}, \mathrm{b}}$ \\ a Mood Disorders Outpatient Program, PROTHUM, Federal University of Rio Grande do Sul, UFRGS/Hospital de Clínicas de Porto Alegre, HCPA, Porto Alegre, \\ Brazil \\ ${ }^{\mathrm{b}}$ Post Graduate Program in Medical Sciences: Psychiatry, Federal University of Rio Grande do Sul, UFRGS, Porto Alegre, Brazil \\ ${ }^{\text {c } A n x i e t y ~ D i s o r d e r s ~ O u t p a t i e n t ~ P r o g r a m ~ f o r ~ C h i l d r e n ~ a n d ~ A d o l e s c e n t s, ~ P R O T A I A, ~ F e d e r a l ~ U n i v e r s i t y ~ o f ~ R i o ~ G r a n d e ~ d o ~ S u l, ~ U F R G S / H o s p i t a l ~ d e ~ C l i ́ n i c a s ~ d e ~ P o r t o ~}$ \\ Alegre, HCPA, Porto Alegre, Brazil \\ ${ }^{\mathrm{d}}$ National Institute of Developmental Psychiatry for Children and Adolescents (INPD/ CNPq), Brazil \\ e Federal University of Rio Grande do Sul, UFRGS, Porto Alegre, Brazil
}

\section{A R T I C L E I N F O}

\section{Article history:}

Accepted 5 January 2016

Available online 8 January 2016

Keywords:

Depression

Treatment-resistant depression

Interpersonal psychotherapy

Randomized pragmatic clinical trial

\begin{abstract}
A B S T R A C T
Background: Treatment-resistant depression (TRD) is an extremely prevalent clinical condition. Although Interpersonal Psychotherapy (IPT) is an established treatment for uncomplicated depression, its effectiveness has never before been studied in patients with TRD in real-world settings. We investigate IPT as an adjunct strategy to treatment as usual (TAU) for TRD patients in a pragmatic, randomized, controlled trial.

Methods: A total of 40 adult patients with TRD (satisfying the criteria for major depressive disorder despite adequate antidepressant treatment) were recruited from a tertiary care facility for this pragmatic trial and blinded to the evaluator. Patients were randomized to one of two treatment conditions: (1) TAU - pharmacotherapy freely chosen by the clinician $(n=23)$ and (2) TAU+IPT $(n=17)$. Assessments were performed at weeks 8,12,19 and 24. Changes in the estimated means of the Hamilton Depression Rating Scale score were the primary outcome measure. Secondary outcomes included patient-rated scales and quality of life scales. We used a linear mixed model to compare changes over time between the two groups.

Results: Both treatments lead to improvements in depressive symptoms from baseline to week 24 with no significant between group differences in either primary: TAU (mean difference: 4.57; CI95\%: 0.59$8.55 ; d=0.73$ ) vs. IPT + TAU (mean difference: 5.86 , CI95\%: $1.50-10.22 ; d=0.93$ ) or secondary outcomes. Limitations: Our relatively small sample limits our ability to detect differences between treatments.

Conclusions: Both treatments lead to equal improvements in depressive symptoms. We found no evidence to support adding IPT to pharmacotherapy in patients with TRD.

Trial registration: ClinicalTrials.gov-NCT01896349.
\end{abstract}

(c) 2016 Elsevier B.V. All rights reserved.

\section{Introduction}

Resistance to therapy is a major concern in major depressive disorder (MDD) treatment. Only one third of patients achieve remission after a pharmacotherapy first attempt and only half exhibit a 50\% reduction in depressive symptoms after 12-14 weeks of medication (Trivedi et al., 2006). Treatment-resistant depression (TRD) is associated with a $40-50 \%$ increase in direct and

\footnotetext{
* Correspondence to: Psychiatry Department, Rua Ramiro Barcelos, 2350, 4th floor, 90.035-903, Porto Alegre, RS, Brazil.

E-mail address: liviahartmanndesouza@gmail.com (L.H. Souza).
}

indirect costs when compared with nonresistant depression (Gibson et al., 2010). Despite the absence of consensus on the definition of TRD (Berlim and Turecki, 2007) testing efficacious treatments for TRD is currently a major goal for the field.

Treatment options for TRD include switching to a different antidepressant (Rush et al., 2006; Fava et al., 2006) or augmenting with another pharmacological agent (Nierenberg et al., 2006; Bauer et al., 2014). The results, however, are still disappointing: approximately $20 \%$ of patients remit after a second antidepressant trial (Rush et al., 2006) and fewer than 20\% remit after a third attempt (Fava et al., 2006). Augmentation strategies with psychological treatments have received considerably less attention in 
the literature, and the available evidence is somewhat mixed. One study evaluated cognitive behavioral therapy (CBT) plus medication versus medication alone for TRD and found that the combined treatment was superior (Wiles et al., 2013). On the other hand, another study evaluating cognitive behavioral analysis system of psychotherapy (CBASP) and brief supportive psychotherapy (BSP) associated with pharmacotherapy failed to find any benefit from combined treatments when compared with pharmacotherapy alone (Kocsis et al., 2009). Despite its proven efficacy for treating depression to date, Interpersonal Psychotherapy (IPT) has never before been tested in TRD populations (Gaynes et al., 2011).

There is strong evidence supporting IPT as an option for depression treatment, either as monotherapy or as in combination with pharmacotherapy (Cuijpers et al., 2011). However, the majority of studies evaluating IPT in combination with pharmacotherapy conducted efficacy trials, with strictly controlled medication, which limits the applicability of such results in clinical practice (Reynolds et al., 1999; Lespérance et al., 2007). Almost all of our current treatment recommendations for MDD are mainly based on efficacy trials, with highly homogeneous and well-defined patients. Nevertheless, there is significant concern over the applicability of such results to daily clinical practice (March et al., 2005). Consequently, given the challenges in treating complex cases of TRD, it is imperative for researchers to test the effectiveness of interventions in real-world settings by making use of more pragmatic designs (March et al., 2010; Ware and Hamel, 2011).

Here, we evaluate IPT in a pragmatic, randomized trial as an augmentation strategy of pharmacotherapy in patients with TRD that actually look for treatment in a tertiary outpatient service. This study was designed to help the clinician make the decision of whether or not to add IPT with treatment as usual (TAU) for TRD patients. We hypothesized that the IPT add-on group would perform better than the pharmacotherapy-only group.

\section{Method}

\subsection{Study design and implementation}

The study is an evaluator-blind, pragmatic, randomized clinical trial comparing (1) TAU versus (2) TAU plus interpersonal psychotherapy (TAU+IPT). Recruitment took place from September 2012 until July 2014 at the Mood Disorder Program (PROTHUM), a tertiary outpatient service of Hospital de Clínicas de Porto Alegre (HCPA) in Brazil. Patients came from primary care units because of treatment failure; most of the patients were already under pharmacological treatment. At the first visit, a diagnostic procedure was performed and inclusion criteria were assessed. All subjects that fulfilled the inclusion criteria and had no exclusion criteria were invited to participate in the study. Once a patient agreed to participate, baseline assessment followed by randomization was performed; the interventions started a week later. The study was approved by the medical ethics committee at HCPA and informed consent was obtained from all participants. The study was registered on ClicalTrials.gov under the following number: NCT01896349. The results of the blood markers will be reported in a future publication.

\subsection{Participants}

The inclusion criteria were a diagnosis of MDD according to the DSM-IV as assessed with the Mini International Neuropsychiatric Interview (MINI). The exclusion criteria were bipolar disorder, psychotic disorder, inability to complete the questionnaires, intellectual disability, high suicide risk, inability to meet trial demands and currently in or having received psychotherapy in the last 4 weeks.

\subsection{Treatment-resistant depression}

TRD was defined as a failure to respond to one trial of antidepressant medication in adequate dose and duration. Adequate dose was defined as the equivalent of at least $75 \mathrm{mg}$ of amitriptyline. Adequate treatment duration was defined as at least four weeks. Patients should be under this antidepressant scheme at the moment of randomization.

\subsection{Randomization and blinding}

Single randomization was carried out by means of sequentially numbered brown sealed envelopes containing the randomization sequence generated by computer prior to the recruitment of subjects. Once a patient agreed to participate and the baseline assessment was performed, the next envelope was opened. Investigators responsible for the outcome assessments were blinded to the treatment assignment.

\subsection{Interventions}

\subsubsection{Interpersonal psychotherapy}

IPT was conducted in accordance with treatment guidelines (Weissman, 2000). IPT is a time-limited psychotherapy with proven efficacy in the treatment of MDD (Cuijpers et al., 2011). IPT has two main principles: (1) depression is a medical illness that is treatable and not the patient's fault, and (2) there is a connection between mood and life events. The focus is on the relationship between MDD episodes and current interpersonal problems, trying to find new ways of dealing with these problems, improving relational functioning, and ultimately relieving depressive symptoms. IPT has four problem areas: grief, interpersonal role dispute, role transitions and interpersonal deficits. The patient and therapist chose the problem area most strongly related to the current episode and work on it during sessions. IPT therapists take an active, non-neutral, supportive and hopeful stance.

The trial included 16 individual 40-min weekly sessions. Three instances of appointment rescheduling were allowed so therapy could last from 16-19 weeks. IPT was administered by third-year psychiatry residents and one psychiatrist. All therapists received at least one year of IPT training before the trial. All sessions were audiotaped and supervised weekly by a senior IPT psychiatric therapist.

\subsection{Treatment as usual - pharmacotherapy plus clinical management}

All participants who enrolled in the study received TAU, i.e., pharmacotherapy plus clinical management. Drug prescription was performed during the clinical management sessions according to MDD treatment guidelines. Clinicians were free to choose antidepressant medication, doses and drug combinations, including augmentations strategies with non-antidepressant drugs, which followed standard clinical guidelines (Bauer et al., 2013; Lam et al., 2009). Clinical management sessions occurred in a monthly basis but clinicians were free to set extra appointments as necessary. The intervention lasted 19 weeks. Clinical management was performed following National Institute of Mental Health (NIMH) guideline recommendations (Fawcett et al., 1987). We focused on psychiatric history, depressive symptoms evaluation and followup, drug side effects management, patient education concerning MDD and pharmacological treatment. Clinicians were instructed to build a warm and collaborative patient-doctor relationship, which in turn promoted treatment compliance. Moreover, adherence to clinical management protocol prevented an overlap between clinical management and IPT. 


\subsection{Outcome measures}

The primary outcome was the Hamilton Depression Rating Scale (HDRS) score as a continuous variable. HDRS is a 17 -item clinician rating depression scale (Hamilton, 1967). Secondary outcomes included the Beck Depression Inventory (BDI) score, which is a 21-item self-report measure that assesses the presence and the severity of depressive symptoms (Beck et al., 1961), the quality of life score, assessed using the World Health Organization Instrument to Assess Quality of Life Brief Version (WHOQOL-BREF) (Fleck et al., 2000), which is a 26-item instrument that measures quality of life in four domains (physical, psychological, social relationship and environment with two additional questions assessing general quality of life), and the Clinical Global Impression (CGI) score, which is a 7-point clinician-rated scale to assess clinical severity ranging from 1 to 7 (Guy, 1976). All of the secondary outcomes were evaluated as continuous variables.

Response to treatment was defined as a $50 \%$ decrease in HDRS score, and remission was defined as HDRS $\leq 7$; both were secondary outcomes calculated for completers and the intention-totreat population (all patients lost to follow-up were presumed to not satisfy the response and remitting criteria). Outcome measures were obtained at 8, 12, 19 and 24 weeks after randomization. Assessment at weeks 8 and 12 was conducted by telephone by research assistants and included BDI and WHOQOL-BREF. Assessment at weeks 19 and 24 included all instruments and was faceto-face and was conducted by a trained psychiatrist blinded to the treatment condition. Blinding was ensured by instructing the patients not to discuss their treatment during assessment.

\subsection{Drug change score}

As a complementary analysis and in order to control for antidepressant medication prescription, we created a medication score. Our objective was to evaluate if both groups were similarly medicated. We refer the reader to the supplemental material for details.

\subsection{Statistical analysis}

We estimated the sample size using data from previous IPT studies. Considering a standard deviation of 6 , we would need a sample size of 32 patients per arm to detect a minimal difference of 5 points in HDRS between groups (considering probabilities of $5 \%$ for type I errors and 10\% for type II errors). Nevertheless, due to difficulties with patient recruitment we were forced to interrupt the trial earlier. Therefore, with our actual sample of 40 subjects our statistical power was $72 \%$.

We performed analyses using the full dataset including all patients randomly assigned to any of the two interventions. We used a linear mixed model to examine changes over time in the two treatment groups in the estimated mean scores of HDRS, CGI, WHOQOL-BREF and BDI. We then tested group, time and group by time interactions. Time was treated as a categorical variable to assess treatment effects at the different time points. To control for potential confounders, our supplemental analysis evaluated the treatment gains after controlling for the effects of the following covariates: (1) baseline HDRS, (2) number of medications added, (3) number of medications subtracted, (4) percent medication dosage increase, and (5) percent medication dosage decrease.

We also evaluated the proportions of responders and remitters using the intention-to-treat sample and the completer sample. We employed a chi-squared test to compare proportions between treatment groups. We adopted two-sided significance tests at the $5 \%$ significance level.

\section{Results}

\subsection{Participants}

A total of 200 patients were assessed for eligibility. Of these individuals, 40 were randomized to one of the two treatment conditions. The CONSORT diagram for the study is presented in Fig. 1. The percentage of participants available for analysis at week 24 was $94 \%$ for the IPT + TAU group and $78 \%$ for the TAU group. There was no significant difference between the groups in terms of attrition rates. All available data from all of the participants were included into the mixed model analysis without imputing any missing data.

The demographic and clinical characteristics of the sample are summarized in Table 1. On average, patients were characterized by 2.57 previous depressive episodes and their current episodes had lasted for nearly 30 months. No statistically significant differences between groups were detected with regard to demographic characteristics, comorbidities or mean baseline depression severity rating scores. Furthermore, no significant differences were found between treatment conditions regarding the number of clinical management sessions and drug scores throughout the trial. The mean number of TAU sessions was 4.27 for the TAU group and 4.53 for the TAU+IPT group. The mean number of IPT sessions was 11.53. Five patients in the TAU+IPT group had fewer than 8 IPT sessions.

\subsection{Outcomes}

\subsubsection{Primary outcome}

The mean depressive symptoms scores on the HDRS significantly improved over time in both conditions from baseline until week 24: TAU (mean difference: 4.57; CI95\%: 0.59-8.55; $d=0.73$; CI95\%: 0.08-1.36) vs. IPT + TAU (mean difference: 5.86, CI95\%: $1.50-10.22 ; d=0.93$; CI95\%: 0.19-1.63). However, there was no significant time by group interactions (Table 2 ). The results remained unchanged after including drug score change and baseline HDRS as covariates (see the Supplemental material). The estimated means from the mixed model are listed in Table 2.

\subsection{Secondary outcomes}

The mean depressive symptoms scores on the BDI (secondary outcome) significantly improved over time in both conditions from baseline until week 24: TAU (mean difference: 6.26; confidence interval for difference: $-2.17-14.70$; $d=0.55$; CI95\%: $0.08-1.15$ ) vs. IPT + TAU (mean difference: 7.96; confidence interval for difference: $-1.66-17.58$; $d=0.70$; CI95\%: -0.03-1.40). Again, there was no significant time by group interaction (Table 2). CGI also improved over time, with no significant time by group interaction (Table 2).

The mean values and standard deviations of the four domains and overall questions of the WHOQOL-BREF are listed in Table 2. We recovered a significant improvement over time in both treatment conditions in the physical domain and in one of the overall QOL questions. We failed to find significant differences over time in the other WHOQOL-BREF domains. There was no significant time by group interaction, except for the social domain.

\subsection{Response and remission}

Considering the intention-to-treat sample the differences in response rates and remission were not significant: TAU $=22.2 \%$ vs. $\mathrm{TAU}+\mathrm{IPT}=35.5 \% \quad\left(\chi^{2}=0.709 ; \quad p=0.40\right) \quad$ and $\mathrm{TAU}=16.7 \% \quad$ vs. $\mathrm{TAU}+\mathrm{IPT}=28.6 \%\left(\chi^{2}=0.653, p=0.419\right)$, respectively. Considering the sample of completers, the differences in response rates and 


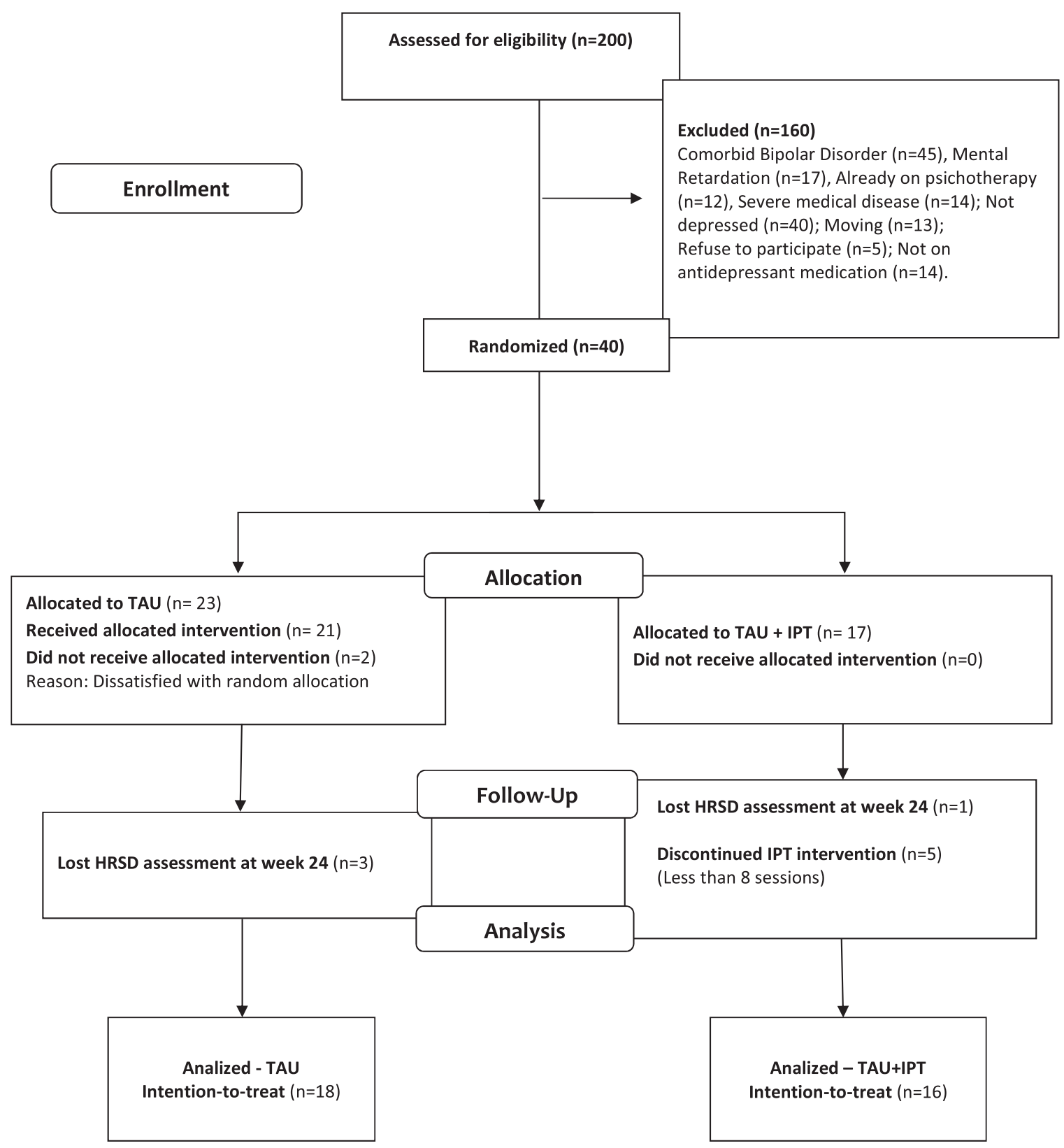

Fig. 1. Trial Flowchart. Notes: TAU, treatment as usual; IPT, Interpersonal Psychotherapy; HDRS, Hamilton Depression Rating Scale.

remission were also not significant: TAU $=22.2 \%$ vs. $\mathrm{TAU}+\mathrm{IPT}=20 \% \quad\left(\chi^{2}=0.019, \quad p=0.891\right) \quad$ and $\mathrm{TAU}=16.7 \% \quad$ vs. $\mathrm{TAU}+\mathrm{IPT}=20 \%\left(\chi^{2}=0.049, p=0.825\right)$, respectively.

\section{Discussion}

We have examined the effectiveness of IPT as augmentation strategy for TRD. Pharmacotherapy, along with clinical management, was effective at reducing depressive symptoms in tertiary care patients with TRD. The addition of IPT did not produce more benefits in terms of depressive symptoms compared with TAU alone. Our sample is clinically representative; patients were voluntarily looking for treatment in a tertiary service (no special recruitment occurred). Pharmacotherapy was delivered without restrictions, in accordance with the clinician's choice. The hypothesis that IPT would yield a larger reduction in depressive symptoms and improvement in quality of life compared with TAU was not supported by our study.

As far as we know, this study is the first to evaluate the effectiveness of IPT as an augmentation strategy for TRD patients (Gaynes et al., 2011; Stimpson et al., 2002). So far, only other psychotherapies have been tested. The STAR-D study evaluated cognitive therapy (CT) (Thase et al., 2007), the CoBalt trial evaluated CBT (Wiles et al., 2013) and the REVAMP trial evaluated CBASP and BSP (Kocsis et al., 2009). In the STAR-D study, CT was compared with medication, both as add-on treatments. The results showed that CT was as effective as medication with a better tolerance and a slower onset (Thase et al., 2007). However, besides using a different psychotherapy, the STAR-D design differed from our own: two augmentation strategies were being compared instead of one augmentation strategy vs. TAU. In the CoBalt trial, two groups were compared: usual care alone vs. usual care plus CBT. Clinicians were free to choose medications. The group that 
Table 1

Sample description.

\begin{tabular}{|c|c|c|c|c|c|c|}
\hline & \multicolumn{2}{|c|}{ TAU $(n=23)$} & \multicolumn{2}{|c|}{ IPT + TAU $(n=17)$} & \multirow[t]{2}{*}{ Statistic } & \multirow[t]{2}{*}{$p$-Value } \\
\hline & $N$ & $\%$ & $N$ & $\%$ & & \\
\hline Gender & & & & & & 0.582 \\
\hline Female & 19 & 82.6 & 15 & 88.2 & $\chi_{(\mathrm{d} f=1)}^{2}=0.303$ & \\
\hline Marital status & & & & & $\chi_{(\mathrm{d} f=3)}^{2}=1.441$ & 0.771 \\
\hline Single & 2 & 9.5 & 2 & 11.8 & & \\
\hline Married & 9 & 42.9 & 8 & 47.1 & & \\
\hline Separated & 10 & 45.5 & 5 & 29.4 & & \\
\hline Widowed & 1 & 4.8 & 2 & 11.8 & & \\
\hline Employment status & & & & & $\chi_{(\mathrm{d} f=7)}^{2}=4.442$ & 0.721 \\
\hline Employed & 4 & 18.2 & 3 & 17.6 & & \\
\hline Unemployed & 4 & 19 & 2 & 11.8 & & \\
\hline Unwaged domestic work & 3 & 14.3 & 1 & 5.9 & & \\
\hline Student & 1 & 4.8 & 0 & 0 & & \\
\hline Disablement benefit & 8 & 38.1 & 6 & 35.3 & & \\
\hline Social class & & & & & $\chi_{(\mathrm{d}}^{2} f_{=4)}=7.393$ & 0.136 \\
\hline Class A/B & 3 & 14.3 & 4 & 23.5 & & \\
\hline Class $\mathrm{C}$ & 18 & 81.8 & 13 & 76.5 & & \\
\hline Class $\mathrm{D} / \mathrm{E}$ & 1 & 4.8 & 0 & 0 & & \\
\hline \multicolumn{7}{|l|}{ Comorbidities } \\
\hline Social phobia & 5 & 23.8 & 2 & 11.8 & $\chi_{(\mathrm{d}}^{2} f_{=1)}=2.250$ & 0.134 \\
\hline Panic disorder & 1 & 4.8 & 1 & 5.9 & $\chi_{(\mathrm{d}}^{2} f_{=1)}=0.026$ & 0.871 \\
\hline Agoraphobia & 5 & 23.8 & 4 & 23.5 & $\chi_{(\mathrm{d}}^{2} f_{=1)}=0.000$ & $>0.999$ \\
\hline Specific phobia & 14 & 66.7 & 8 & 47.1 & $\chi^{2}\left(d f_{=1)}=0.823\right.$ & 0.364 \\
\hline OCD & 1 & 4.8 & 4 & 23.5 & $\chi_{(\mathrm{d}}^{2} f_{=1)}=1.702$ & 0.192 \\
\hline PTSD & 1 & 4.8 & 0 & 0 & $\chi_{(\mathrm{d}}^{2} f_{=1)}=0.823$ & 0.364 \\
\hline GAD & 7 & 33.3 & 7 & 41.2 & $\chi^{2}(\mathrm{~d} f=1)=0.024$ & 0.877 \\
\hline FH of psychiatric disorder & 20 & 90.9 & 16 & 94.1 & $\chi^{2}\left(d f_{=1)}=0.193\right.$ & 0.718 \\
\hline \multirow[t]{2}{*}{ FH of depression } & 12 & 54.5 & 12 & 70.6 & $\left.\chi_{(\mathrm{d}}^{2} \mathrm{f}=1\right)=1.043$ & 0.471 \\
\hline & Mean & SD & Mean & SD & Statistic & p-Value \\
\hline Age (years) & 49.18 & 12.5 & 49.3 & 12.31 & $t_{(\mathrm{d} f=37)}=-0.314$ & 0.987 \\
\hline Years of education & 9.6 & 2.66 & 7.94 & 4.25 & $t_{(\mathrm{d} f=35)}=1.350$ & 0.183 \\
\hline \multicolumn{7}{|l|}{ Depression } \\
\hline $\mathrm{N}$ of depressive episodes & 2.57 & 2.15 & 2.4 & 1.35 & $t_{(\mathrm{d} f=34)}=0.271$ & 0.788 \\
\hline Current episode (months) & 29.05 & 27.33 & 33.5 & 36.64 & $t_{(\mathrm{d} f=37)}=-0.432$ & 0.668 \\
\hline First episode - Age & 35.67 & 16.26 & 35.7 & 16.61 & $t_{(\mathrm{d} f=35)}=-0.004$ & 0.997 \\
\hline \multicolumn{7}{|l|}{ Baseline outcomes scores } \\
\hline \multicolumn{7}{|l|}{ Whoqol domains scores } \\
\hline Physical health & 36.86 & 11.17 & 34 & 12.79 & $t_{(\mathrm{d} f=34)}=0.203$ & 0.840 \\
\hline Psychological & 36.11 & 14.45 & 36.9 & 16.8 & $t_{(\mathrm{d} f=34)}=-0.159$ & 0.874 \\
\hline Social & 49.6 & 18.72 & 52.2 & 20.28 & $t_{(\mathrm{d} f=34)}=-0.400$ & 0.692 \\
\hline Environmental & 47.02 & 11.06 & 50.2 & 13.74 & $t_{(\mathrm{d} f=34)}=-0.769$ & 0.447 \\
\hline Overall 1 & 9.65 & 6.01 & 12.5 & 5.5 & $t_{(\mathrm{d}} f_{=36)}=-1.480$ & 0.148 \\
\hline Overall 2 & 8.3 & 5.7 & 7.81 & 6.25 & $t_{(\mathrm{d}} f_{=35)}=0.264$ & 0.793 \\
\hline HDRS score & 18.45 & 5.28 & 19.8 & 5.06 & $t_{(\mathrm{d}} f_{=37)}=-0.817$ & 0.419 \\
\hline BDI score & 28.86 & 8.04 & 31.4 & 11.62 & $t_{(\mathrm{d}} f_{=37)}=-0.790$ & 0.435 \\
\hline CGI score & 4.23 & 0.97 & 4.47 & 0.62 & $t_{(\mathrm{d}} f_{=37)}=-0.897$ & 0.375 \\
\hline \multicolumn{7}{|l|}{ Treatment conditions } \\
\hline \multicolumn{7}{|l|}{ Drug scores: baseline to $24 \mathrm{w}$} \\
\hline Drugs added & 0.86 & 0.79 & 1.29 & 0.98 & $t_{(\mathrm{d}} f_{=36)}=-1.516$ & 0.138 \\
\hline Drugs subtracted & 0.57 & 0,81 & 1 & 0.93 & $t_{(\mathrm{d} f=36)}=-1.513$ & 0.139 \\
\hline$\%$ Drug dose increase & 119.7 & 112.04 & 74.47 & 76.94 & $t_{(\mathrm{d}} f_{=36)}=1.415$ & 0.166 \\
\hline \% Drug dose decrease & 9.90 & 24.65 & 4,12 & 12.78 & $t_{(\mathrm{d}} f_{=36)}=0.876$ & 0.387 \\
\hline $\mathrm{N}$ of TAU sessions & 4.27 & 1.35 & 4.53 & 8.74 & $t_{(\mathrm{d}} f_{=37)}=-0.680$ & 0.501 \\
\hline $\mathrm{N}$ of IPT sessions & & & 11.53 & 3.59 & & \\
\hline
\end{tabular}

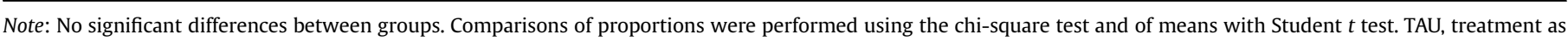

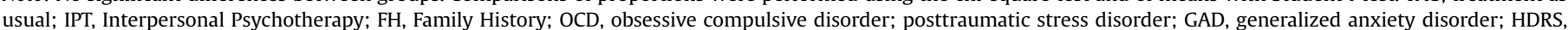
Hamilton Depression Rating Scale; BDI, Beck Depression Inventory; CGI, Clinical Global Impression; 24w, 24 weeks. 
Table 2

Linear mixed models of TAU or TAU+IPT in TRD.

\begin{tabular}{|c|c|c|c|c|c|c|c|c|c|c|c|c|c|}
\hline & \multicolumn{2}{|l|}{ Baseline } & \multicolumn{2}{|l|}{ Week 8} & \multicolumn{2}{|l|}{ Week 12} & \multicolumn{2}{|l|}{ Week 19} & \multicolumn{2}{|l|}{ Week 24} & \multicolumn{3}{|l|}{$p$-Value } \\
\hline & TAU & IPT + TAU & TAU & IPT + TAU & TAU & IPT + TAU & TAU & IPT + TAU & TAU & IPT + TAU & Time & Group & $\mathbf{T}^{*} \mathbf{G}$ \\
\hline HDRS & $\begin{array}{l}18.4 \\
(\mathrm{SE}=1.3)\end{array}$ & $\begin{array}{l}19.8 \\
(\mathrm{SE}=1.5)\end{array}$ & & & & & $\begin{array}{l}13.8 \\
(\mathrm{SE}=1.4)\end{array}$ & $\begin{array}{l}12.3 \\
(\mathrm{SE}=1.7)\end{array}$ & $\begin{array}{l}13.9 \\
(\mathrm{SE}=1.4)\end{array}$ & $\begin{array}{l}14.0 \\
(\mathrm{SE}=1.6)\end{array}$ & $<0.001$ & 0.986 & 0.322 \\
\hline CGI & $\begin{array}{l}4.2 \\
(\mathrm{SE}=0.2)\end{array}$ & $\begin{array}{l}4.5 \\
(\mathrm{SE}=0.3)\end{array}$ & & & & & $\begin{array}{l}3.2 \\
(\mathrm{SE}=0.2)\end{array}$ & $\begin{array}{l}3.0 \\
(\mathrm{SE}=0.3)\end{array}$ & $\begin{array}{l}3.4 \\
(\mathrm{SE}=0.3)\end{array}$ & $\begin{array}{l}3.2 \\
(\mathrm{SE}=0.3)\end{array}$ & $<\mathbf{0 . 0 0 1}$ & 0.874 & 0.501 \\
\hline BDI & $\begin{array}{l}28.9 \\
(\mathrm{SE}=2.5)\end{array}$ & $\begin{array}{l}31.3 \\
(\mathrm{SE}=2.8)\end{array}$ & $\begin{array}{l}28.9 \\
(\mathrm{SE}=2.7)\end{array}$ & $\begin{array}{l}29.7 \\
(\mathrm{SE}=3.1)\end{array}$ & $\begin{array}{l}27.9 \\
(\mathrm{SE}=2.6)\end{array}$ & $\begin{array}{l}25.3 \\
(\mathrm{SE}=2.9)\end{array}$ & $\begin{array}{l}22.3 \\
(\mathrm{SE}=2.6)\end{array}$ & $\begin{array}{l}26.0 \\
(\mathrm{SE}=3.0)\end{array}$ & $\begin{array}{l}22.6 \\
(\mathrm{SE}=2.5)\end{array}$ & $\begin{array}{l}23.4 \\
(\mathrm{SE}=2.9)\end{array}$ & 0.001 & 0.742 & 0.520 \\
\hline \multicolumn{14}{|c|}{ WHOQol-B domains } \\
\hline Physical & $\begin{array}{l}34.9 \\
(\mathrm{SE}=3.3)\end{array}$ & $\begin{array}{l}32.6 \\
(\mathrm{SE}=3.8)\end{array}$ & $\begin{array}{l}33.7 \\
(\mathrm{SE}=4.1)\end{array}$ & $\begin{array}{l}39.9 \\
(\mathrm{SE}=4.4)\end{array}$ & $\begin{array}{l}34.8 \\
(\mathrm{SE}=4.1)\end{array}$ & $\begin{array}{l}41.1 \\
(\mathrm{SE}=4.3)\end{array}$ & $\begin{array}{l}39.4 \\
(\mathrm{SE}=3.4)\end{array}$ & $\begin{array}{l}44.1 \\
(\mathrm{SE}=4.1)\end{array}$ & $\begin{array}{l}39.7 \\
(\mathrm{SE}=3.4)\end{array}$ & $\begin{array}{l}46.8 \\
(\mathrm{SE}=3.9)\end{array}$ & 0.027 & 0.320 & 0.304 \\
\hline Psychological & $\begin{array}{l}36.1 \\
(\mathrm{SE}=3.8)\end{array}$ & $\begin{array}{l}36.3 \\
(\mathrm{SE}=4.3)\end{array}$ & $\begin{array}{l}40.4 \\
(\mathrm{SE}=5.1)\end{array}$ & $\begin{array}{l}44.7 \\
(\mathrm{SE}=5.3)\end{array}$ & $\begin{array}{l}43.0 \\
(\mathrm{SE}=5.2)\end{array}$ & $\begin{array}{l}42.0 \\
(\mathrm{SE}=5.4)\end{array}$ & $\begin{array}{l}42.6 \\
(\mathrm{SE}=4.0)\end{array}$ & $\begin{array}{l}42.7 \\
(\mathrm{SE}=4.7)\end{array}$ & $\begin{array}{l}40.8 \\
(\mathrm{SE}=3.9)\end{array}$ & $\begin{array}{l}43.8 \\
(\mathrm{SE}=4.4)\end{array}$ & 0.061 & 0.799 & 0.940 \\
\hline Social & $\begin{array}{l}49.6 \\
(\mathrm{SE}=4.4)\end{array}$ & $\begin{array}{l}50.1 \\
(\mathrm{SE}=5.0)\end{array}$ & $\begin{array}{l}37.9 \\
(\mathrm{SE}=5.3)\end{array}$ & $\begin{array}{l}56.3 \\
(\mathrm{SE}=5.7)\end{array}$ & $\begin{array}{l}42.8 \\
(\mathrm{SE}=5.4)\end{array}$ & $\begin{array}{l}59.4 \\
(\mathrm{SE}=5.7)\end{array}$ & $\begin{array}{l}46.8 \\
(\mathrm{SE}=4.5)\end{array}$ & $\begin{array}{l}49.7 \\
(S E=5.4)\end{array}$ & $\begin{array}{l}51.6 \\
(\mathrm{SE}=4.4)\end{array}$ & $\begin{array}{l}47.3 \\
(\mathrm{SE}=5.1)\end{array}$ & 0.852 & 0.236 & 0.014 \\
\hline Environmental & $\begin{array}{l}47.0 \\
(\mathrm{SE}=3.8)\end{array}$ & $\begin{array}{l}49.5 \\
(\mathrm{SE}=4.3)\end{array}$ & $\begin{array}{l}49.5 \\
(\mathrm{SE}=6.1)\end{array}$ & $\begin{array}{l}52.6 \\
(\mathrm{SE}=6.1)\end{array}$ & $\begin{array}{l}51.7 \\
(\mathrm{SE}=6.1)\end{array}$ & $\begin{array}{l}47.7 \\
(\mathrm{SE}=6.2)\end{array}$ & $\begin{array}{l}49.6 \\
(\mathrm{SE}=4.1)\end{array}$ & $\begin{array}{l}63.0 \\
(\mathrm{SE}=5.1)\end{array}$ & $\begin{array}{l}47.3 \\
(\mathrm{SE}=3.9)\end{array}$ & $\begin{array}{l}51.1 \\
(\mathrm{SE}=4.4)\end{array}$ & 0.368 & 0.359 & 0.485 \\
\hline Overall 1 & $\begin{array}{l}9.7 \\
(\mathrm{SE}=1.1)\end{array}$ & $\begin{array}{l}12.5 \\
(\mathrm{SE}=1.3)\end{array}$ & $\begin{array}{l}12.0 \\
(\mathrm{SE}=1.6)\end{array}$ & $\begin{array}{l}14.2 \\
(\mathrm{SE}=1.6)\end{array}$ & $\begin{array}{l}11.4 \\
(\mathrm{SE}=1.6)\end{array}$ & $\begin{array}{l}13.0 \\
(\mathrm{SE}=1.7)\end{array}$ & $\begin{array}{l}13.4 \\
(\mathrm{SE}=1.2)\end{array}$ & $\begin{array}{l}13.9 \\
(\mathrm{SE}=1.4)\end{array}$ & $\begin{array}{l}13.1 \\
(\mathrm{SE}=1.2)\end{array}$ & $\begin{array}{l}13.9 \\
(\mathrm{SE}=1.3)\end{array}$ & 0.025 & 0.281 & 0.676 \\
\hline Overall 2 & $\begin{array}{l}8.4 \\
(\mathrm{SE}=1.2)\end{array}$ & $\begin{array}{l}7.7 \\
(\mathrm{SE}=1.4)\end{array}$ & $\begin{array}{l}9.7 \\
(\mathrm{SE}=1.7)\end{array}$ & $\begin{array}{l}7.7 \\
(\mathrm{SE}=1.8)\end{array}$ & $\begin{array}{l}10.0 \\
(\mathrm{SE}=1.8)\end{array}$ & $\begin{array}{l}8.0 \\
(\mathrm{SE}=1.9)\end{array}$ & $\begin{array}{l}9.6 \\
(\mathrm{SE}=1.3)\end{array}$ & $\begin{array}{l}10.40 \\
(\mathrm{SE}=1.5)\end{array}$ & $\begin{array}{l}8.7 \\
(\mathrm{SE}=1.3)\end{array}$ & $\begin{array}{l}12.3 \\
(\mathrm{SE}=1.5)\end{array}$ & 0.056 & 0.970 & 0.074 \\
\hline
\end{tabular}

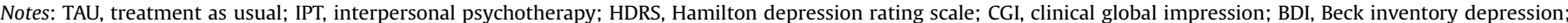
WHOQOL-B, World Health Organization Instrument to Assess Quality of Life (brief version); T, time; G, Group.

$p$-Value $<0.05$ in bold font.

${ }^{a}$ Linear mixed models.

received CBT had higher rates of remission than the usual care alone group. In terms of response and remission rates, the CoBalt trial exhibited comparable results to ours (response: CBT 46\%, TAU $22 \%$; remission: CBT 28\%, TAU 15\%), although our results were not statistically significant. As in our trial, CoBalt patients had long current depressive episodes ( > 24 months duration: CBT 58\%, TAU $60 \%$ ) (Wiles et al., 2013). In the REVAMP trial, patients were chronically depressed and had not responded to one antidepressant trial, just as in our sample. The authors of the REVAMP trial compared: (1) continued pharmacotherapy and augmentation with CBASP, (2) continued pharmacotherapy and augmentation with BSP, and (3) continued optimized pharmacotherapy alone. There was an algorithm to guide pharmacotherapy. As in our trial, all arms equally improved; there were no differences between treatment groups (Kocsis et al., 2009). Therefore, among three large trials that evaluated psychotherapy as an add-on for TRD, two trials did not find any benefit of this treatment strategy over the other strategy that was tested. We should note that there is a stricter criterion for TRD, which is failure after two previous antidepressant treatments instead of one (Berlim and Turecki, 2007). Also, some authors have advocated that response without remission, the need for additional treatments (Fleck and Horwath, 2005), and an unsatisfactory response to treatment when it is delivered under non-ideal conditions (Rush et al., 2003) are better defined as difficult-to-treat depression rather than TRD. Nevertheless, the definitions are still controversial and many other studies adopted the same criterion as we used (Wiles et al., 2013; Kocsis et al., 2009).

Besides being treatment-resistant, our sample is also chronic. Psychotherapy in general is less effective for chronically depressed patients than for non-chronically depressed patients (Cuijpers et al., 2010). Moreover, it has been advocated that chronically depressed patients necessitate longer treatments (at least 18 sessions) (Cuijpers et al., 2010); our sample received on average 11 sessions. This fact may explain why we could not find benefits of adding IPT to this population. Considering IPT studies for non-resistant depression, one meta-analysis evaluated IPT as a treatment for depression (Cuijpers et al., 2011). The mean effect size indicating the difference between IPT along with pharmacotherapy vs. pharmacotherapy alone was small and not statistically significant: $d=0.16 \quad(\mathrm{CI} 95 \%=-0.03-0.36 ;$ number needed to treat $=11.11$ ) in favor of combination treatment. We can conclude from this study that if one of these two treatments is superior the difference is small. Moreover, all studies that we have focused on were efficacy trials, which limits their applicability to real-world practice. A study like ours, on the other hand, requires IPT to perform better in order to supersede pharmacotherapy.

In agreement with the need for more pragmatic designs, Peeters et al. (2013) reported an effectiveness trial comparing CT, IPT and pharmacotherapy. Unlike our investigation, this trial compared psychotherapy alone with combined treatment, instead of pharmacotherapy alone. Additionally, the treatment was chosen via mutual agreement by the patient and therapist. As in our trial, patients from all treatment arms equally improved with no significant differences among them (Peeters et al., 2013). This fact may be a consequence of adopting a more pragmatic design, which dilutes the treatment effects because of its heterogeneity and non-controlled nature (Patsopoulos, 2011).

Moreover, the majority of individuals in our sample have a low socioeconomic status and are exposed to many kinds of stress: poverty, family drug problems, violence, etc. We hypothesize that the continuous exposure to stressful life events overwhelms a patient's capacity to actively deal with these stressors, as the IPT technique proposes. In accordance with our hypothesis, one study found that clinical management was superior to IPT for patients with low functioning and low social support (Lespérance et al., 2007), and IPT was not superior to clinical management for patients with a high baseline of social dysfunction (Sotsky et al., 1991). What may occur is that our patients cannot simultaneously deal with IPT demands plus chronic stress exposure; they may do better with the lower demands of regular clinical management (Lespérance et al., 2007).

The present study has some limitations. First, our small sample limits our ability to detect differences between treatments, and the 
trial had to be interrupted earlier than previously expected. Second, our therapists were psychiatry residents, which could have reduced the quality of the psychotherapy (even though all therapists were trained and received weekly supervision). Third, inherent to our pragmatic design, the medication was the clinician's free choice, which could favor a bias between groups; we did control for this variable and could not find any difference. On the other hand, this limitation makes our study more generalizable to clinical practice. Our study also has some important strengths: to our knowledge, this study is the first to evaluate IPT in a TRD sample. Moreover, this investigation is the first to do so with a pragmatic design that helps clinician decide whether or not to add IPT to usual care for TRD patients.

In conclusion, TRD is a large challenge to clinical psychiatry and there is an urgent need for effective treatments. According to our study, IPT was not effective as adjunctive treatment. Larger trials are needed to rule out more discrete effects from IPT, which could not be detected by our research.

\subsection{Supplemental material}

In order to control for antidepressant medication prescription we created a medication score. Our objective was to evaluate if both groups were similarly medicated. The following items were computed: (1) the number of drugs added, (2) the number of drugs subtracted, (3) the percentage of dose increase (starting from the lowest therapeutically dose and considering the initial and final dose), and (4) the percentage of dose decrease for each patient from baseline until week 24 . For example, consider a patient who entered the study receiving fluoxetine $20 \mathrm{mg}$, and during the trial his or her fluoxetine dose was increased to $60 \mathrm{mg}$ and amitriptyline was added and then increased to a dosage of $150 \mathrm{mg}$. This patient have the following score: (1) drugs added: 1 point, (2) drugs subtracted: zero points, (3) percentage of drug increase: $300 \%$ of fluoxetine plus $100 \%$ of amitriptyline starting from $75 \mathrm{mg}$, for a total of $400 \%$, (4) percentage of dose decrease: $0 \%$. Each one of the items was individually considered one covariate in the supplemental analysis.

\section{Appendix A. Supplementary material}

Supplementary data associated with this article can be found in the online version at http://dx.doi.org/10.1016/j.jad.2016.01.004.

\section{References}

Bauer, M., Adli, M., Ricken, R., Severus, E., Pilhatsch, M., 2014. Role of lithium augmentation in the management of major depressive disorder. CNS Drugs 28 , 331-342. http://dx.doi.org/10.1007/s40263-014-0152-8.

Bauer, M., Pfennig, A., Severus, E., Whybrow, P.C., Angst, J., Möller, H.-J., 2013. World Federation of Societies of Biological Psychiatry. Task Force on Unipolar Depressive Disorders, 2013. World federation of societies of biological psychiatry (WFSBP) guidelines for biological treatment of unipolar depressive disorders, part 1: update 2013 on the acute and continuation treatment of unipolar depressive disorders. World J. Biol. Psychiatry J. World Fed. Soc. Biol. Psychiatry 14, 334-385. http://dx.doi.org/10.3109/15622975.2013.804195.

Beck, A.T., Ward, C.H., Mendelson, M., Mock, J., Erbaugh, J., 1961. An inventory for measuring depression. Arch. Gen. Psychiatry 4, 561-571.

Berlim, M.T., Turecki, G., 2007. What is the meaning of treatment resistant/refractory major depression (TRD)? A systematic review of current randomized trials. Eur. Neuropsychopharmacol. J. Eur. Coll. Neuropsychopharmacol. 17 696-707. http://dx.doi.org/10.1016/j.euroneuro.2007.03.009.

Cuijpers, P., Geraedts, A.S., van Oppen, P., Andersson, G., Markowitz, J.C., van Straten, A., 2011. Interpersonal psychotherapy for depression: a meta-analysis. Am. J. Psychiatry 168, 581-592. http://dx.doi.org/10.1176/appi.ajp.2010.10101411.

Cuijpers, P., van Straten, A., Schuurmans, J., van Oppen, P., Hollon, S.D., Andersson, G., 2010. Psychotherapy for chronic major depression and dysthymia: a metaanalysis. Clin. Psychol. Rev. 30, 51-62. http://dx.doi.org/10.1016/j. cpr.2009.09.003.
Fava, M., Rush, A.J., Wisniewski, S.R., Nierenberg, A.A., Alpert, J.E., McGrath, P.J., Thase, M.E., Warden, D., Biggs, M., Luther, J.F., Niederehe, G., Ritz, L., Trivedi, M. H., 2006. A comparison of mirtazapine and nortriptyline following two consecutive failed medication treatments for depressed outpatients: a STAR*D report. Am. J. Psychiatry 163, 1161-1172. http://dx.doi.org/10.1176/appi. ajp.163.7.1161.

Fawcett, J., Epstein, P., Fiester, S.J., Elkin, I., Autry, J.H., 1987. Clinical management imipramine/placebo administration manual. NIMH treatment of depression collaborative research program. Psychopharmacol. Bull. 23, 309-324.

Fleck, M.P., Horwath, E., 2005. Pharmacologic management of difficult-to-treat depression in clinical practice. Psychiatr. Serv. Wash. DC 56, 1005-1011. http: //dx.doi.org/10.1176/appi.ps.56.8.1005.

Fleck, M.P. Louzada, S., Xavier, M., Chachamovich, E., Vieira, G., Santos, L., Pinzon, V. 2000. [Application of the Portuguese version of the abbreviated instrument of quality life WHOQOL-bref]. Rev. Saúde Pública 34, 178-183.

Gaynes, B.N., Lux, L.J., Lloyd, S.W., Hansen, R.A., Gartlehner, G., Keener, P., Brode, S., Evans, T.S., Jonas, D., Crotty, K., Viswanathan, M., Lohr, K.N., 2011. Nonpharmacologic Interventions for Treatment-Resistant Depression in Adults, AHRQ Comparative Effectiveness Reviews. Agency for Healthcare Research and Quality (US), Rockville (MD).

Gibson, T.B., Jing, Y., Smith Carls, G., Kim, E., Bagalman, J.E., Burton, W.N., Tran, Q.-V., Pikalov, A., Goetzel, R.Z., 2010. Cost burden of treatment resistance in patients with depression. Am. J. Manag. Care 16, 370-377.

Guy, W., 1976. Assessment Manual for Psychopharmacology. US Government Printing Office.

Hamilton, M., 1967. Development of a rating scale for primary depressive illness. Br. J. Soc. Clin. Psychol. 6, 278-296.

Kocsis, J.H., Gelenberg, A.J., Rothbaum, B.O., Klein, D.N., Trivedi, M.H., Manber, R., Keller, M.B., Leon, A.C., Wisniewski, S.R., Arnow, B.A., Markowitz, J.C., Thase, M. E., 2009. REVAMP Investigators, 2009. Cognitive behavioral analysis system of psychotherapy and brief supportive psychotherapy for augmentation of antidepressant nonresponse in chronic depression: the REVAMP trial. Arch. Gen. Psychiatry 66, 1178-1188. http://dx.doi.org/10.1001/ archgenpsychiatry.2009.144.

Lam, R.W., Kennedy, S.H., Grigoriadis, S., McIntyre, R.S., Milev, R., Ramasubbu, R., Parikh, S.V., Patten, S.B., Ravindran, A.V., 2009. Canadian Network for Mood and Anxiety Treatments (CANMAT), 2009. Canadian Network for Mood and Anxiety Treatments (CANMAT) clinical guidelines for the management of major depressive disorder in adults. III. Pharmacotherapy. J. Affect. Disord. 117 (Suppl. 1), S26-43. http://dx.doi.org/10.1016/j.jad.2009.06.041.

Lespérance, F., Frasure-Smith, N., Koszycki, D., Laliberté, M.-A., van Zyl, L.T., Baker, B., Swenson, J.R., Ghatavi, K., Abramson, B.L., Dorian, P., Guertin, M.-C., 2007. CREATE Investigators, 2007. Effects of citalopram and interpersonal psychotherapy on depression in patients with coronary artery disease: the Canadian cardiac randomized evaluation of antidepressant and psychotherapy efficacy (CREATE) trial. J. Am Med. Assoc. 297, 367-379. http://dx.doi.org/10.1001/ jama.297.4.367.

March, J., Kraemer, H.C., Trivedi, M., Csernansky, J., Davis, J., Ketter, T.A., Glick, I.D., 2010. What have we learned about trial design from NIMH-funded pragmatic trials? Neuropsychopharmacology 35, 2491-2501. http://dx.doi.org/10.1038/ npp.2010.115.

March, J.S., Silva, S.G., Compton, S., Shapiro, M., Califf, R., Krishnan, R., 2005. The case for practical clinical trials in psychiatry. Am. J. Psychiatry 162, 836-846. http://dx.doi.org/10.1176/appi.ajp.162.5.836.

Nierenberg, A.A., Fava, M., Trivedi, M.H., Wisniewski, S.R., Thase, M.E., McGrath, P.J., Alpert, J.E., Warden, D., Luther, J.F., Niederehe, G., Lebowitz, B., Shores-Wilson, K., Rush, A.J., 2006. A comparison of lithium and T(3) augmentation following two failed medication treatments for depression: a STAR*D report. Am. J. Psychiatry 163, 1519-1530. http://dx.doi.org/10.1176/appi.ajp.163.9.1519 (quiz 1665).

Patsopoulos, N.A., 2011. A pragmatic view on pragmatic trials. Dialog- Clin. Neurosci. $13,217-224$

Peeters, F., Huibers, M., Roelofs, J., van Breukelen, G., Hollon, S.D., Markowitz, J.C. van Os, J., Arntz, A., 2013. The clinical effectiveness of evidence-based interventions for depression: a pragmatic trial in routine practice. J. Affect. Disord. 145, 349-355. http://dx.doi.org/10.1016/j.jad.2012.08.022.

Reynolds 3rd, C.F., Frank, E., Perel, J.M., Imber, S.D., Cornes, C., Miller, M.D., Mazumdar, S., Houck, P.R., Dew, M.A., Stack, J.A., Pollock, B.G., Kupfer, D.J., 1999. Nortriptyline and interpersonal psychotherapy as maintenance therapies for recurrent major depression: a randomized controlled trial in patients older than 59 years. J. Am. Med. Assoc. 281, 39-45.

Rush, A.J., Thase, M.E., Dubé, S., 2003. Research issues in the study of difficult-totreat depression. Biol. Psychiatry 53, 743-753. http://dx.doi.org/10.1016/ S0006-3223(03)00088-X.

Rush, A.J., Trivedi, M.H., Wisniewski, S.R., Stewart, J.W., Nierenberg, A.A., Thase, M. E., Ritz, L., Biggs, M.M., Warden, D., Luther, J.F., Shores-Wilson, K., Niederehe, G., Fava, M., 2006. STAR*D Study Team, 2006. Bupropion-SR, sertraline, or venlafaxine-XR after failure of SSRIs for depression. N. Engl. J. Med. 354, 1231-1242. http://dx.doi.org/10.1056/NEJMoa052963.

Sotsky, S.M., Glass, D.R., Shea, M.T., Pilkonis, P.A., Collins, J.F., Elkin, I., Watkins, J.T., Imber, S.D., Leber, W.R., Moyer, J., 1991. Patient predictors of response to psychotherapy and pharmacotherapy: findings in the NIMH treatment of depression collaborative research program. Am. J. Psychiatry 148, 997-1008. http://dx. doi.org/10.1176/ajp.148.8.997.

Stimpson, N., Agrawal, N., Lewis, G., 2002. Randomised controlled trials investigating pharmacological and psychological interventions for treatment- 
refractory depression. Systematic review. Br. J. Psychiatry J. Ment. Sci. 181, 284-294.

Thase, M.E., Friedman, E.S., Biggs, M.M., Wisniewski, S.R., Trivedi, M.H., Luther, J.F., Fava, M., Nierenberg, A.A., McGrath, P.J., Warden, D., Niederehe, G., Hollon, S.D., Rush, A.J., 2007. Cognitive therapy versus medication in augmentation and switch strategies as second-step treatments: a STAR*D report. Am. J. Psychiatry 164, 739-752. http://dx.doi.org/10.1176/ajp.2007.164.5.739.

Trivedi, M.H., Rush, A.J., Wisniewski, S.R., Nierenberg, A.A., Warden, D., Ritz, L., Norquist, G., Howland, R.H., Lebowitz, B., McGrath, P.J., Shores-Wilson, K., Biggs, M.M., Balasubramani, G.K., Fava, M., 2006. STAR*D Study Team, 2006. Evaluation of outcomes with citalopram for depression using measurement-based care in STAR*D: implications for clinical practice. Am. J. Psychiatry 163, 28-40. http://dx.doi.org/10.1176/appi.ajp.163.1.28.

Ware, J.H., Hamel, M.B., 2011. Pragmatic trial - guides to better patient care? N Engl. J. Med. 364, 1685-1687. http://dx.doi.org/10.1056/NEJMp1103502.

Weissman, M.M., 2000. Comprehensive Guide to Interpersonal Psychotherapy, Basic Behavioral Science. Basic Books, New York.

Wiles, N., Thomas, L., Abel, A., Ridgway, N., Turner, N., Campbell, J., Garland, A. Hollinghurst, S., Jerrom, B., Kessler, D., Kuyken, W., Morrison, J., Turner, K., Williams, C., Peters, T., Lewis, G., 2013. Cognitive behavioural therapy as an adjunct to pharmacotherapy for primary care based patients with treatment resistant depression: results of the CoBalT randomised controlled trial. Lancet 381, 375-384. http://dx.doi.org/10.1016/S0140-6736(12) 61552-9. 